\title{
Clubhouse Community Support for Life: Staff-Member Relationships and Recovery
}

\author{
Kimiko Tanaka ${ }^{1} \cdot$ Tom Craig $^{2} \cdot$ Larry Davidson $^{3}$
}

Received: 3 November 2015/Accepted: 19 November 2015/Published online: 9 December 2015

(C) Springer India Pvt. Ltd. 2015

\begin{abstract}
With signs that early interventions for severe mental illness have at best only a modest impact on longerterm outcome, a need for a long-term care and support system that facilitates recovery is resurfacing. This article describes a well-established long-term support program, the clubhouse model, drawing on qualitative interview data from 105 users and 25 staff from five clubhouses in the U.S. and Finland, which was analyzed using a grounded theory approach. Recurrent patterns of transformative life changes emerged. Central to these processes was a sense of equality between staff and members that transcended social roles and mental health status and was experienced as embodying trust in human potential and respecting member's choice. This staff-member relationship can be framed by the Aristotelian notion of friendship for life. The clubhouse, offering a home base to which members can return in times of need, may provide a viable safety net for recovery.
\end{abstract}

Keywords Clubhouse $\cdot$ Community $\cdot$ Friendship $\cdot$ Staffmember relationship $\cdot$ Recovery

Kimiko Tanaka

ktanaka@maryu.marywood.edu

1 School of Social Work, Marywood University, 2300 Adams Avenue, Scranton, PA 18509, USA

2 Institute of Psychiatry, King's College London, London, UK

3 Department of Psychiatry, Yale University School of Medicine, New Haven, CT, USA

\section{Introduction}

With signs that early interventions for severe mental illness $[1,2]$ have at best only a modest impact on longer term outcome [3], a need for a long term care and support system that facilitates recovery and avoids institutionalization [4] is resurfacing [5, 6]. Systematic research, however, has yet to promote the use of long-term care programs, such as the clubhouse model, despite their long-standing existence internationally. The purpose of this study is to describe the clubhouse model in relation to recovery, with recovery being defined as "a process of change through which individuals improve their health and wellness, live a selfdirected life, [and] strive to achieve their full potential" [7, para 2].

Clubhouse for mental health recovery is a non-governmental non-profit organization that provides a communitybased, non-residential approach to psychosocial rehabilitation for adults who have serious mental illness [8-10]. The clubhouse has been replicated internationally and as of 2015, there are about 150 clubhouses certified in compliance with the Clubhouse International (CI) Standards [11], with the most in the U.S., followed by Finland. The current model consists of: Work-Ordered Day; Employment; Evening, Weekend, and Holiday activities; Community Support; Reach-Out; Education; Housing; and DecisionMaking and Governance programs [12]. The "WorkOrdered Day" (WOD) is central to the model in that all program activities are designed around it $[12,13]$. The structure of the WOD parallels that of a typical organization in the world of work and encourages members to participate voluntarily in operating the clubhouse.

Clubhouse programs have been said to directly address societal and personal reactions conspiring to prevent recovery by providing a space in which everyone is 
genuinely needed and valued, where staff and members work side by side as equals, and membership is elastic rather than being constrained by the artifice of a treatment 'dose' [5]. Clubhouse research has begun to identify such a "space" as a community [14-17] that provides a wealth of mutual social support for recovery [14-21]. Aspects of the clubhouse community support have been described in terms of the overall community support as well as its peer component $[22,23]$.

Somewhat surprisingly, there have been few efforts to describe the nature of recovery within the context of the clubhouse model. Norman's [24] study of a Swedish clubhouse found multiple aspects of rehabilitation process (e.g., gradual increase in activity involvement, the sense of inclusion, and the social network size, and as discovery or rediscovery of one's resources to accomplish and contribute). Another study at an Australian clubhouse [25] suggested that later recovery stages in the clubhouse context assume distinct characteristics such as accepting one's illness and acquiring control over symptoms, loving oneself and becoming optimistic, doing things as pleasure, making contributions via meaningful activity, feeling needed and valued by others, diversifying friendships, and coming to terms with one's family. One study [26] at a U.S. clubhouse described older members' lived experiences of the staff as support provider, which were both positive (e.g., good will) and negative (concern about the reliability and quality of the relationship). To the authors' knowledge, only the above three studies described either recovery processes or the support provided by staff, yet each on the basis of one clubhouse and none focused on how members and staff see how the staff contributes to members' recovery as process. Hence, the present study enquires of both members and staff at multiple clubhouses: What is recovery like in the clubhouse context? What constitutes essential support in the recovery process? How might the staff play a role in it?

\section{Method}

The present study drew upon qualitative data collected as part of IRB-approved mixed methods study conducted in 2009-2013 at five certified clubhouses (two in the U.S. and three in Finland). One hundred five members (45 for New York [NY], 35 for Ohio [OH], and 24 for southern Finland) and 26 staff $(11,10$, and 5 , respectively) participated in $1 \mathrm{~h}$ and $1.5-2 \mathrm{~h}$, respectively, in-depth interviews using openended questions and probes on their experiences of clubhouse, particularly the WOD. The first author led all interviews except six $\mathrm{OH}$ staff interviews conducted by a colleague in the $\mathrm{OH}$ study. A bilingual Finnish research assistant fully interpreted one Finnish staff and 10 member interviews; all others were conducted in English. $\mathrm{OH}$ member participants received $\$ 5$ for transportation.

Of the member sample, $65 \%$ were males. All were age 69 or younger with the mode 50-59 (30\%). The length of membership ranged from 1 week to 39 years (39\% for 3 years or less). Participants, on average, were participating in WOD for $5.0(\mathrm{SD}=1.7)$ hours per day and 3.5 $(\mathrm{SD}=1.3)$ days per week. Of the staff participants, females consisted of $70 \%$ of the $\mathrm{OH}$ sample, compared to $50 \%$ each of the other two. The demographic patterns were not meaningfully different across the three geographical locations.

Data were analyzed using a grounded theory approach $[27,28]$. The initial data (45 members) from one U.S. clubhouse were first open-coded and then, with 10 selected transcripts, line-by-line coding was iterated to develop focused codes, based on which constant comparison was continued for trustworthiness with the remaining transcripts within the initial data set as well as those from the other data sets. The staff interviews were used to supplement member interviews. (More detailed methodological procedures were described elsewhere [29]).

\section{Findings}

Our in-depth interview data indicated that people at the clubhouse, members and staff alike, had seen remarkable improvements in members' lives. Some participants described these improvements as "miracles" (narrated in the plural form), while another referred to them as "classic" stories. Still others made change-of-life statements such as "[The clubhouse] changed my life" or "The clubhouse saved my life."

Pat, a NY clubhouse member, for instance, described her peer members' transformative improvement, as "miracles," which "really gravitated" her to the clubhouse:

There are miracles that I've seen happen there. It's indescribable ... it's like somebody coming from a deep coma, after a long period of time and the doctors have given up on this person and the family members or the extended surrogates uh, it, you know when they sign the proxy, do not resuscitate, DNR ... a person as vegetating ... I kind of see them in that kind of deep coma and their slowly uh, coming around, evolving and uh, but it's on a very slow, sometimes you can't see it with the naked eye, but eventually, after I would say, before 3 months there is a definite, uh, duration of improvement.

Participants described the processes surrounding such improvement mostly as gradual, accompanying an increased involvement in the core program, the WOD. 
Their explanations for these change-of-life processes included acceptance of mental illness, medicine, social support, and personal efforts to improve health (exercise, healthy diet, hobby such as games, taking a break, reading books, etc.), as well as just "doing" and the will to improve (taking responsibility to recover, sticking to the program, etc.). But of all these the most extensively described was the social support that members experienced within the clubhouse. Interestingly, one of the social support subthemes that recurrently emerged was friendship, as Pat above accounted for her peers' improvement:

It wasn't so much how beautiful and captivating uh and, and how can I put it? Cozy and hospitable and just so inviting the place was. And people accepted you for you, not that they were throwing pity parties and being, uh condescending. Cause sometimes people can be very subtle in patronizing somebody. But mostly, mostly people can see right through it.

But it was just, you know, you're a regular pal...

A question remains, however, as to what this "regular pal" means. Does this mean that all relationships in the clubhouse are friendships, including staff-member ones, which, intuitively, would seem unequal? Merriam Webster's Collegiate Dictionary [30, p. 467], defining friend as "one attached to another by affection or esteem," does not seem to exclude friendship among unequals, but how are they, then, "friends"? How does the friendship help members' recovery? To answer these questions, we will focus on the nature of clubhouse member-staff relationship from the perspectives of both members and staff with the focus on life-saving, or transformative, phenomena, identified as a recurrent theme. The following sections will be organized mainly around three participants' narratives (two members, $\mathrm{Al}$ and Lea, and one staff, Meg) as the core, which, together, seemed to cover most comprehensively the extracted themes. We will present members' personal accounts of their transformations, first, in the context of WOD, and then in staff-member relational contexts. We will then describe how the staff-member relationship in general might relate to the transformative processes, with our particular interest in member-staff equality.

\section{Clubhouse Changed My Life}

\section{The WOD was There for Me when I Needed It}

Participants' change-of-life or life-saving stories often suggested an underlying transformation of self, which appeared embedded in the WOD. The transformative processes, typically reflected in changes in their remarks from "I can't" to "I can," seemed to entail a shift from distrust, through a nascent sense of trust, to trust in self, others, and the world. The following two members' accounts exemplify these transformations.

Lea Lea, a Finnish member, returned to school after her regular WOD participation, recently completed her university degree, and came back to her clubhouse for respite from the hard schoolwork in service of getting ready for a job. She first came to the clubhouse with no self-respect after her hospitalization; however, "slowly and gradually," as she recalls, regained her trust in her ability to do WOD tasks, step by step and day by day, to see hope:

I didn't believe in me because when you get mental illness, all of your self-respect disappears ... your self-esteem goes away. And today I see that I have been in the kitchen ... making food for 60 people. It came by it's like baby steps you know ... very slowly, very gradually, you start to notice these positive things about yourself, you start to think in a positive way. I am able to do this, now maybe I can do that. Now I have been working [for WOD]. Now maybe I can be working [for a job] one day and start to get these potentials.

Lea places a special value on the clubhouse that helped her to rebuild her life: "It is absolutely the best thing that happened. ... It's very important here that you see your potential. You see what someone could be."

Al Al, a NY member, also described how he had made personal growth after joining the clubhouse. Now "pretty much ... on [his] own," he feels certainty in his direction as a musician with passion and productivity while keeping his job to part-time to effectively manage his "stressful" work environment in a competitive company, where his boss constantly looks for "every fault." About 10 years ago, a friend of his brought him to the clubhouse when he still had difficulty getting out of bed after using mental health services more than three years. The clubhouse, he recalls, "saved my life" by helping him strengthen a sense of direction and purpose thereby adding a "meaning to [his] life."

$\mathrm{Al}$ ascribed his growth to his "stick-to-itness" in the WOD, during his first couple of years at the clubhouse. He participated 3-5 days a week, which gave him "structure" for a day through which he experienced "a feeling of, wow, now I'm doing something," a success which in turn motivated him "to do something a few hours from now" and set goals for the next day, or "things to look forward." He would say to himself: "Okay, everyday I'm going to do something... It's just going to get me out of bed, and get me thinking more positively about my life, even if it's a small, little thing that I do." He described how the small achievements in the step-by-step approach of the WOD 
gave him a positive sense of his ability and a hope that kept him moving forward-transformative processes whereby a sense of trust in himself and life emerged and grew: "There was something there that was going to help you do something, and say to yourself, ok I accomplished something today, therefore I feel better about myself. ... and then maybe that would translate in other areas of my life. It was a positive reinforcement." $\mathrm{Al}$ appreciates the power of the accumulation, over time, of seemingly trivial, activities: "All those years of doing the little things, you don't think of them as important but they become part of who you are."

\section{Staff was Always There for Me}

Participants' accounts also suggested how such transformations of self and life may unfold in the context of relationships fostered through collaboration within the context of the WOD. Those relationships included staffmember relationships. Some members talked about a particular staff whose presence meant a lot to them. Lea, for instance, recalled about a staff whose interest she came to find similar to hers through ordinary conversations during leisure times between WOD tasks. This staff member played a pivotal role in her decision to return to school:

[She] was much of a role model to me in many ways because she liked studying and she liked to talk about eating healthy. Things like that. How to lead a normal life was an important quality for a role model. She had a normal life. She had a family and she was working and painting and stable. Mentally stable.

Al also was appreciative of a staff member, Jane, with whom he worked closely for WOD and who had a shared interest in music: "I learned to trust myself, and my own place, and little things that [Jane] would do." Al elaborates on his sense of trust by describing how doing WOD chores with staff side by side on a daily basis had a profound impact on his sense of self. He discovered not only his ability to accomplish things for himself but also his ability to give something to others, thereby experiencing what it means to be part of society. Al recollected how Jane in particular gave him a long-term trusted companionship he perhaps needed in this journey "back into society":

Working with [her] 3 to 4 days a week ... really helped to get me back into society. It helped to make me realize, have a sense of self-worth, and also appreciate that there's a greater good to helping out, even the little chores we do like sweeping the floor, mopping, cleaning the bathrooms. These little things, she made me feel very important [part of running the clubhouse] when, at the end of the day, when I would accomplish tasks, and she would be like, ok, now it's time to relax.

What Al learned from Jane appears deeply ingrained in his way of life today. Jane, now deceased, is alive in his mind as a social worker and as a "friend," still showing up in times of need:

And there would be times when I feel not very selfassured, that I could say to myself, I know and loved [her], as a friend, as a social worker, as someone who I could always go to when there was no one else to lift me up ... I say to myself, just pick yourself up, cause that's what [she] would want you to do. She would want you to just move ahead, and not think about the things that are holding you back.

\section{Is Staff-Member Relationship Equal or Non-equal?}

In our previous study, we found several ingredients, or ordinary interactional patterns, that appeared to constitute the clubhouse "atmosphere" that members appreciated as supportive. We named these ingredients 'clubhouse ways,' which included: welcoming greetings, a focus on work instead of mental illness, gentle push or encouragement, choice and pace, no-one-is-perfect spirit, and recognition and appreciation. On the one hand, these clubhouse ways appeared to be associated with certain conceptions about staff members over time, a view which, seemingly, can imply a rather unbalanced staff-member relationship that involves little "give and take." Said Al: "[They are] always there to give their time and their energy and they try to keep things positive for us so we can lead better lives." On the other hand, participants emphasized the equality of the staff-member relationship they experienced through the clubhouse way. Al also talked of a balance between staff and members which he describes as being together: "There's no distinguishing between one and the other ... you don't want a social structure in terms of having the feeling that the staff is more important than the client. There's always a balance of we're all in this together." In the following, we will explore how these two contradictory messages might be reconciled.

First, Lea referred to the equality of members and staff and where the sense of balance might come from:

I feel equal when I come inside this door. I feel like this is like a home, it is somewhere I belong, nobody asks me about my illness, everybody knows that I have some problems in my life but I don't have to talk about it. ... it's important because I can still keep my integrity and nobody is telling you what to do, you choose what you want to do everyday. 
In contrast, her experience of the hospital was quite different. Here her "integrity" felt fragmented because her choice-or the representation of who she was as a whole person-for "what you want to do everyday" was not heard; nor was her choice respected for what she did not want to do: "At the hospital ... you are naked when you are sick ... at least I needed this distance in the beginning to other people before I was ready to open up." As if the patient knew nothing and the staff knew all, the hospital seemed to separate staff and patients and make nonnegotiable the hierarchy between them-a style of relating which, no matter what the intention might be on the hospital's part, could be experienced as worsening the already undermined sense of an "equal" value as a human on the patient's part.

The clubhouse way, by contrast, with its emphasis on choice, appears to help reverse the dehumanizing processes experienced outside, not only in the hospital but also in the community in general (e.g., group homes). Lea comes to see human value underlying the right to choice and integrity: "It comes from your value, you get the value, everybody talks to you like an equal. There is nobody telling you what to do ... I can make my choices, it's my own life and I have a right to my integrity." Thus, Lea gradually regained her sense of trust in her self, from a nascent form ("I am still a human being with a value") to an assertive one ("I feel equal ... my choices ... my own life ... a right to my integrity").

Ordinary decision-making scenes $\mathrm{Al}$ portrayed below pinpoint in what contexts Lea might have experienced her everyday choices for what she wants or does not want to do being respected. That is, the sense of choice, or of being an equal in decision-making, is typically and somewhat paradoxically facilitated by how staff encourage, or gently push, members to get involved in WOD, which, according to $\mathrm{Al}$, was more a "helpful nudge," but not being forced:

You'll see it at the meetings; it will be like this-how about you, how about you. They sort of suggest, but it's sort of a suggestion that sort of like nudging you, sort of, in a way. But ... it's not a deterrent to feeling like I'm being forced into something ... it's so democratic because we all do it out of our own wanting to do it.

Of course, this emphasis on personal choice can be difficult at times, especially if someone keeps saying 'no' to invitations. Meg, an $\mathrm{OH}$ staff, found a resolution for this kind of conflict in the welcoming and no-one-is-perfect spirit of the clubhouse way to remain inclusive: "Even if they aren't willing to do something, you're friendly to people. You're nice to people. You engage them in conversation. Um, if they're having difficulties with something, you advocate with them to get something taken care of. Relationship, relationship, relationship."

The human value assumption Lea sees beneath the right to choice also surfaced and resurfaced throughout the interviews with other participants. Al, for example, pointed out that: "Everyone has some value; that's an indigenous part of [the clubhouse] is that we all have value." Participants described how the clubhouse encourages members to explore, discover, and cultivate their own strengths as actualized forms of human value or potential. The staff appeared keen to recognize members' real interests, talents, and successes as well as their contributions to the clubhouse, no matter how small they may be. Meg underscored the importance of this kind of encouragement made on the basis of recognition of these strengths: "Oh, I see you did that. Or, I understand you're interested in that. How would you like to do this with me? You have a great speaking voice. How would you like to answer the phones? Would you like me to show you how to answer the phones?" Meg also emphasized another critical element of encouragement, which is to raise members' awareness that their talents and successes are not merely personal values, but also social values by showing: "some enthusiasm into what it is I'm doing ... why it's important ... I need someone who can work with me." A Finnish staff, Vienna, recalled a member, Ira, who now has a job in her recovery and who explained to her later that she said yes to the work partly because she saw the clubhouse "really needed it".

The side-by-side mode of work collaboration, while forming an optimal context in which the staff can stay tuned to members' strengths and needs, also may be experienced as a gentle push yet as a safe ambience to get any assistance whenever needed. Meg illustrated how she coached members in concrete skills side by side, which, over time, could transform the "No, I can't" self into the "Yes, I can" self:

It blows my mind every time somebody says to me, 'I don't know how to do that.' Or ... 'What do I do now?' ... Over time it changes because we're right there side-by-side. Okay. Pick it up. Push the button that's blinking. 'Good morning. This is [Clubhouse]. ... How may I help you?' 'Just a minute please.' 'They want to talk to you. What do I do?' 'Put it on hold. See that red button there. Press hold. Hang up the phone. I'll go pick it up.' Side-by-side, step by step. And people then begin to feel comfortable because they're not gonna make a mistake, cause we're right there. I mean, [a member], when she came in never answered the phone. Now it's the first thing she volunteers to do. 'I'll answer [it].' She doesn't always do it right. It's not the end of the world. 
Members appreciated the manner the staff guides them to move forward in their lives not only by inviting them to get involved in work and but also by following up on their accomplishments with "positive reinforcement" to encourage them do more: "They're always here to show up, when you complete tasks, when you do stuff in the positive direction to help improve the quality of your life, there's always recognition." ( $\mathrm{Al})$ The recognition typically comes with appreciation of their strength to make a contribution to the clubhouse. A Finnish member, Esa, was appreciative of people saying "thank-you" for his daily contribution to the clubhouse through watering plants. As $\mathrm{Al}$ indicated earlier, members expressed their sense of selfworth about being able to give, which seemed to mean "getting back to society:" “... not only that I was part of something important, but that I played an integral part in helping things move ... I could contribute to society in a greater way."

In summary, the key to the clubhouse relationship lies at one sense in the experience or realization that staff and members are equal at some fundamental level (as Lea said, "Everybody talks to you like an equal" or says Ano, a Finnish member, "[Staff] cleaning the toilets, or ... sitting in the same [lunch] table ... feels equal in that way, yeah"); but at another sense in how, unlike patients in traditional settings who might stay in the patient role or become institutionalized, members find themselves, via a nascent sense of trust in self and others ("I don't know, but I'll try"), less in need, more in charge of their own lives as opposed to being supervised by someone in power, and more empowered to give; thereby feeling more "balanced" or more equalized. The staff at their best, through the clubhouse ways that embody trust in human potential and respect for choice, appears to play a key role in creating a clubhouse atmosphere that facilitates the transformative processes. In our last results section below, we will describe how staff and members alike, who, as partners or colleagues, work together for common goals, appreciate this second sense of equality as well.

\section{Appreciated Mutuality, Equality, and Unity Despite Differences}

Andy, an $\mathrm{OH}$ member, described the "best" example of two-way decision making, as opposed to the military topdown "orders, the do this, do that," and working together as equals among equals in the clubhouse context. With his empowered tone, he articulated a sense of ownership and unity, or the solidarity of the clubhouse enclave he was part of, yet merging into the outside community:

Do you want to do this? Do you want to do that? And, uh, here's what we're doing today to get ready for the conference ... we hosted.... That was fun ... you saw the clubhouse model working the best. We had this room full every day, cramming ideas ... Who do you know where we can get things for our little tote bags? You know, cause everybody at a conference gives you tote bag with junk in it. Uh, we were working on that. Um, and then trying to come up with, uh, the topics for the conference and the breakouts and stuff like that. And I was part of going around picking the hotel, the team that the house selected. You know, [staff] ... didn't say, "You will go and be on the team." The [club] house voted ... this person, that person, and me and two staff members. ... we went ... around to the different hotels and had chefs' tables and we let you show off your hotel ... why do I want to pick your hotel and not this one? And ... even when we picked the one hotel that we picked, um, another hotel sent flowers to our hotel ... to say we're so pleased the way the [club] house handled themselves and stuff like that... [Likewise], we all voted on what we would do for the conference. Uh, it was no "I" statements. We, I think, can do this.

Staff also reported the mutual support for running the clubhouse as enlightening, although the notion of mutuality seemed to be a "delicate" matter or a challenge to the staff because of their paid responsibility for caregiving. Linda, a NY staff, recalled how she came to grasp the concept of "dependency" on members as trusted "partners." One morning during her early days at clubhouse, she was the only staff available in the kitchen to prepare 200 lunches. She "felt alone ... in panic," with no anticipation that she could do it, when "a lightening force" came to her:

I am not alone ... am surrounded by bright energetic members who do this day in and day out. They're my partners. We are in this together. I got it. And it's not that it was simple but that was my lightening point, that I understood absolutely the reality and dependency on partnership with members. I was dependent. It was first time I experienced dependency ... $100 \%$ dependency on members. ... for the members, no big deal. ... They were doing their morning the way the mornings always happens. There was nothing different. I was different.

Both staff and members, while appreciating the sense of equality and unity, also seemed mutually respectful of boundaries on the basis of understanding and care for another as a separate being. Al, for instance, was clear about the paid staff role:

[Staff] are out to help. ... [I] feel ... good that there are boundaries that you don't cross. That there's certain amount of respect that you have to earn when 
you get to know [them]... just because they have their lives and you have your lives. ... I have a lot of friends here who are [staff]. But I'm always aware of the fact that there are certain things that you can't form relationships like in an intimate level ... it's not a healthy thing... That's not what [the clubhouse] is for.

From the staff side, Meg, the $\mathrm{OH}$ staff, was also explicit about the staff's ultimate responsibility for members' rehabilitation:

If the information from the referral logs isn't in the database correctly, it's my fault. Not that we're looking to put the fault on anybody, but that's my responsibility ... And it's my responsibility to get people involved in doing what needs to be done. Members, it's not their responsibility to get other people involved. So, it's my responsibility to help people to rehabilitate.

With this said, Meg also described how reciprocity between staff and member can unfold in the context of a trusting relationship because it intrinsically motivates the individual to do more than she or he or others may expect:

The other day [one guy] just didn't want to do anything at all ... I was trying to get this information into the computer and it was, you know, this ... and that interruption. And ... he said, 'I'll help you'... I had a relationship with that guy for a long time, for eight years, and I know he wasn't feeling well ... they changed his medicine.

As a person, Meg sounded deeply touched by this member's unexpected giving that came from his heart. Also as a staff member, she sees it as his strength to be able to care for others despite his debilitating condition and, perhaps, his best effort to focus on work to forget the mental illness. This in turn seemed to give her profound respect for the clubhouse, which affirmed not only her ability to help members "make a difference" but also her trust in human potential and resilience:

Being part of a clubhouse is important to me because I feel I make a difference. Um, because I believe that people can recover. Because I think a lot of people who have mental illness have gotten the short end of a stick, and I want to see that stop. And because I think that people who have mental illness have the ability to work. And I guess that's, that's about it.

Viena, the aforementioned Finnish staff, also described mutuality between her and members. Although she defined herself as a "paid professional," whose ultimate responsibility differentiates staff and members, she also underscored staff-member equality, indicating how her relationships with members were reciprocal. For example, members took leadership in lieu of her without bossing her. She also sounded open to learn from members.

Equality means that member can lead ... any process, it's okay with me, I'm enjoying it a lot, I have learned a lot from members ... I learned to make PowerPoint with members, ... we were doing this church concert for raising money ... he was the main organizer, whole concert, and I was assistant to him ... he is a qualified ... opera singer, he has network, and all these things, I felt okay to just be an assistant to him, and learn from him.

She believes that the power of the clubhouse model lies in the idea of equality in "human resources," which has been always her "basic value" since her youth, was the very reason she chose this profession, and today she believes "more than ever": “... whole human being ... a matter of ... [human] resources, like strengths and talents ... In the clubhouse context ... we can use all the resources because members have that active role and are giving their talent for the community." She sees an intrinsic reward in her giving "a voice for people to have equality" in "human resources" because it in turn gives her a "reason to live, to remind our society that, even though people have mental disease, it's not all, they have many talents and things ... It's part of being human."

Common across the three staff accounts above is a view that is consistent with the members' insights-that all humans have potentials that are valuable, both "personally and socially." This view sounded deeply ingrained in who the staff were, as if all they needed to do to become an equal was just to be themselves. Lassi, a Finnish member, was precise in articulating his view on staff-member equality. Like other participants, he enjoyed working side by side, which meant to him "being equal." He was pleasantly surprised with how the staff can be equal so "effortlessly" despite their formal role:

It doesn't matter, if you are a member or staff ... If someone from outside came in, he couldn't tell who is staff ... which is amazing actually ... (Do you think that is just an outlook? Or real equality there?) ... I think it's more real equality ... Everybody is doing the same work here. Of course there are certain responsibilities for staff. But ... that's just something there is, but otherwise there is no difference and I really appreciate our staff. Because they really can do that. They can really be equal ... So it's quite amazing that the staff here can be equal. I mean, and they do it so effortlessly ... Very easily ... (When did you feel very equal with the staff? ...) Almost all the 
time actually. (So it's like friends.) Yeah, like friends, yes. ... (What do you see differences, in terms of ... responsibilities?) ... Mostly dealing ... the financial things ... of course they have, or they should have the overall responsibility of running the house, but fortunately that doesn't show. (Oh, it's not as clear.) Yeah. (... so there are some difference, but those do not undermine the equality ...) Exactly.

Just as Jane, Al's staff, reminded him in his worries, to "stop thinking about things" and "just go on" with his life, Vienna, the staff above, recalls what Ira mentioned earlier: "[During WOD] she forgot she was suffering from mental illness ... just forget, it disappeared ... feeling, lack of selfesteem and bad experiences, [etc.]" Leaving the mental illness hut behind and simply focusing on work as a person seems to work well for recovery. Similarly, recovery in the clubhouse context also appears to depend on the staff's ability to leave the staff hut elsewhere and just to be a person - the paradox of staff's role not being a staff_-or perhaps, as Pat in the beginning said, "just ... a regular pal," and do things together.

\section{Discussion}

The purpose of the present study was to understand the process of recovery in the clubhouse context and the staff component of support for this process from members' and staff's perspectives. Recurrent themes of members' transformative life changes emerged. Participants described gradual processes in which members' incremental involvement in the core program appeared to reflect their gaining or regaining sense of personal and social values thereby "getting a life back" and coming to feel "part of society." Participants attributed the transformation in part to the clubhouse's safe and friendly milieu in which staff being there to include members as equals for work collaboration through "clubhouse ways," which seemed experienced as a way of relating to oneself as "being a human with a value" despite limitations-everyday experiences that appeared to accumulate over time into a sense of trust in themselves, others, and ultimately the world. The being-a-human-of-equal-value experience seemed to form a turning point toward the member's healing and growth, whereby the member comes to feel less in need and has more to give, or the staff-member relationship being more balanced, or equalized. No noticeable differences in these themes were found across the three geographical locations.

The present findings from multiple clubhouses not only add to the clubhouse literature a detailed description of recovery process and the staff component of support but also offer additional qualitative data that reinforce the importance of what has been proposed as "the principle of personhood" for recovery [31, p. 25, 32-37]; that is, any human relationship, including practitioner-client relationship, that respects the personhood of one or both parties involved institutes "a kind of Archimedean point" [33, p. 258, 38-40] of healing and transformation toward recovery. As summarized above, our study findings certainly support this formulation.

In discussing whether the relationship that embodies such respect for personhood is friendship or not, we find Aristotle's view of the nature of the friendship to provide very useful guidance. We close our discussion by viewing these clubhouse data through this philosophical lens, offering an initial argument about the importance of friendship to the recovery process:

Aristotle, in his Nicomachean Ethics ([NE]; [41]), writes that friendship, revolving around mutual love, constitutes the common thread across all kinds of good-natured relationships, whether among equals (e.g., peers) or unequals (e.g., parent-child or leader-follower); or whether at personal (e.g., marital), community (e.g., religious communities, colleagues, soldiers, or political communities), or civic (e.g., cities or countries) levels. He identified three ends of friendship, pleasure (company), utility (material resources), and good, or virtue, (genuine care for another), with the first two being instrumental, or so-called self-centered, purposes and the third, involving others' happiness as sources of one's happiness in person-centered, or healthy self-love [41-44]. A "complete," "true," or "lasting" friendship evolves around the virtue end, seeking friendship as its end, which in turn meets the other two ends as well. Some other defining features of friendship according to Aristotle that are clearly visible in clubhouse relationships included: equality, reciprocity, benevolence, trust, shared activity, shared history, commitment, another self, concord, and partiality [41].

Clubhouse staff-member relationships in the Aristotelian light may be framed as friendships "between unequals" "in community." As Aristotle [41, 1159b§5] writes, mutual care is the way "how unequals as well as equals can be friends" because it can equalize unequals in that they are "similar in being virtuous." Blum [45, p. 81] elaborates on this Aristotelian notion of equality in virtue by adding that the moral value of friendship is to care and act for another "simply as a human being," irrespective of "any special connection or attachment one has with him," or, in Thomas' [46] terms, beyond social roles. Thus, clubhouse staff cares and acts for a member as humanand as the unique person he or she is [42] - for his or her wellbeing (virtue). The member, in turn, responds (reciprocity) to the virtue by helping the staff for the clubhouse community welfare (virtue) - two-way interactions 
that share humanity as the common ground, notwithstanding mental health status, social roles, or the formal hierarchy inherent in any organizational structure. In the Aristotelian paradigm, the staff-member equalization, can be reframed, perhaps more precisely, as the act of friendship, which assumes fundamental human equality, involving a shift in its mode or aspect from the care (virtue-utility) mode for the sake of the other in need to the doing-together (pleasure-utility) mode as the member restores energy to take less and give more.

Contemporary Aristotelian concepts [42, 43, 45-56] also inform what may be named a friendship-for-life process. Friends trust one another in goodwill (benevolence) and judgment concerning the other's welfare on the basis of understanding and respecting for who and what the friend is. The trust keeps them receptive and open to one another's perspective, thereby playing an active role in mutually transforming the other's core value concerning what is important in life, or the core identity. Through a history of shared life involving daily reciprocal interactions that transcend social roles via shared activities over timesharing decision-making processes dealing with shared views, values, and interests, which promote shared commitment to shared actions, and shared consequences including happiness and disappointment. The shared history also reflects parallel, and perhaps intricately related, transformations that deepen one's knowledge about, trust in, and friendship to the self and other-processes which, reinforcing a similar mindset and mutual understanding of the other as another self, also foster a sense of belonging (concord) and form a community of friends with its own existence and value. Partiality, if not completely, is inherent in friendship because of its special concern for one another.

In the clubhouse context, the WOD sets a stage for a shared everyday life. If the member likes the milieu, she may come back, begin to trust the place and the self, and say yes to a WOD chore. The nascent form of trust evolves over time through shared daily WOD activities. The member experiences shared decision-making processes involving shared discussions over WOD task-related practical matters and subsequent commitment to shared actions to accomplish the task of her choice. Consequences of the WOD activities are then shared with others' recognition and appreciation of her success (good job!) and contribution (thank you!). The history of shared everyday life entails the clubhouse way of two-way interactions embodying the shared fundamental clubhouse values (choice and worth), influencing who she or he is. The member, internalizing the clubhouse like-mindset and ways to relate to the self and others, experiences a special or partial feeling toward her or his community of people, or a sense of belonging to the clubhouse, thereby merging into the society. The phenomenon seems to hold in the staffmember-specific relational context.

The conception of staff-member friendship requires future elaboration on several grounds. First, the friendship appears to fall somewhere between personal and civic friendships; thus may be named "community friendship" because, akin to collegial relationship in the world of work, it shares the clubhouse community life domain. Such classification, however, requires further clarification as to how it differs from the other types, particularly personal friendship. Second, the present focus was the best staffmember friendship vis-à-vis members' transformations. As Hietala [16] suggests, members may come to the clubhouse for various reasons. If their primary motivation remains as utility or pleasure, they may not gain as much in the way of meaningful benefits as those who form true friendships. How best to help them form meaningful relationships requires further discussions. Third, the study was limited to the staff-member relational context of transformative processes. As Aristotle [41] noted, one may never be a perfect friend for all. Meaningful friendship entailing profound transformations, such as the ones presented in this article, may be, then, relatively unusual. In order to understand the community friendship within the clubhouse, where such transformations did not appear as uncommon as outside, future studies should look into the whole dynamics by examining both staff-member and peer relational contexts as well as their possible synergistic effects. As part of the dynamics, transformation, or equalization, experiences on the staff part, only presented on a supplemental basis in this study, also call for further elaboration. Last, the current findings also are limited because only one researcher analyzed the data. Some preliminary findings, presented at international clubhouse workshops, received positive responses, which can be compared to member-checking [57]; however, different researchers may yield different interpretations.

Despite these limitations, the rich first-person experiences appear to speak for the clubhouse staff support for recovery as community friendship for life-perhaps as a way to directly address the lost or damaged friendship in the general community. Writes Davidson [58, p. 30]: "Building a friendship of excellence is what will truly define one's process of recovery" [34, 35].

In the era of brief intervention, the friendship framework can pose important challenges for practice oriented to mental health recovery. Our concern resides in the possible breakdown of friendship networks - not only instrumental user-practitioner friendship of some benefits, but also optimal friendships, involving a long-term shared life as is central to recovery. The clubhouse community friendship for life, offering a home base to which people can return in times of need, may provide a viable safety net for recovery. 
Acknowledgments We would like to express our sincere appreciation of the research partnership provided by the clubhouses under study and the contribution made by all the study participants as well as by colleagues (James Mandiberg, Eric Stein, Carrie Baxter, Courtney Connor, Melody Collins, Laura Tarkiainen, and Evan Baier) for their assistance during the research administration.

\section{References}

1. Bertelsen M, Jeppesen P, Petersen L, Thorup A, Øhlenschlæger J, le Quach P, et al. Five-year follow-up of a randomized multicenter trial of intensive early intervention vs standard treatment for patients with a first episode of psychotic illness: The OPUS Trial. Arch Gen Psychiatry. 2008;65(7):762-71.

2. Craig T, Garety P, Power P, Rahaman N, Colbert S, FornellsAmbrojo M, et al. The Lambeth Early Onset (LEO) Team: randomized controlled trial of the effectiveness of specialized care for early psychosis. BMJ. 2004;329(7474):1067-71.

3. Gafoor R, Craig T, Garety P, Power P, McGuire P. Do the benefits of early intervention (EI) treatments for schizophrenia persist? Eur Psychiatry. 2009;24(1):S113.

4. Nordenntoft M, Rasmussen JØ, Melau M, Hjorthøj CR, Thorup A. How successful are first episode programs? A review of the evidence for specialized assertive early intervention. Curr Opin Psychiatry. 2014;27(3):167-72.

5. Craig T. Clubhouse and the future: challenges and opportunities. Paper presented at the 2nd international symposium on clubhouse research, Stockholm, Sweden; 2013, Aug 8-9.

6. Craig T. Clubhouse and the future: challenges and opportunities. Paper presented at the jubilee congress of the world association of social psychiatry, London, UK; 2014 Nov 13-15.

7. The U.S. Substance Abuse and Mental Health Services Administration [Internet]. Recovery is possible. 2015 [cited Oct 4]. http://www.mentalhealth.gov/basics/recovery/index.html.

8. Doyle A, Dudek K, Lanoir J. Fountain House. New York: Columbia University Press; 2013.

9. Clubhouse International [Internet]. About us. 2015 [cited 2015 Oct 4]. http://www.iccd.org/about.html.

10. Hänninen E. Choice for recovery: community-based rehabilitation and the Clubhouse Model as means to mental health reforms. National Institute for Health and Welfare; 2012.

11. Clubhouse International [Internet]. International Standards for Clubhouse Programs. 2015 [cited 2015 Oct 4]. http://www.iccd. org/quality.html.

12. Clubhouse International [Internet]. How Clubhouses function. 2015 [cited 2015 Oct 4]. http://www.iccd.org/function.html.

13. Beard J, Propst R, Mulamud T. The Fountain House model of psychiatric rehabilitation. Psychosoc Rehabil J. 1982;5(1):47-53.

14. Carolan M, Onaga E, Pernice-Duca F, Jimenez T. A place to be: the role of clubhouses in facilitating social support. Psychiatr Rehabil J. 2011;35(2):125-32.

15. Herman SE, Onaga E, Pernice-Duca F, Oh S, Ferguson C. Sense of community in clubhouse programs: member and staff concepts. Am J Community Psychol. 2005;36:343-56.

16. Hietala O. Fluid orientations and multiple meanings: three complementary modes of membership at Clubhouse. Paper presented at the 2nd international symposium on clubhouse research, Stockholm, Sweden; 2013 Aug 8-9.

17. Pernice-Duca F, Onaga E. Examining the contribution of social network support to the recovery process among clubhouse members. Am J Psychiatr Rehabil. 2009;12:10-30.

18. Macias C, Rodican CF. Coping with recurrent loss in mental illness: unique aspects of clubhouse communities. J Pers Interpers Loss. 1997;2:205-21.
19. Pernice-Duca F. The structure and quality of social network support among mental health consumers of clubhouse programs. J Community Psychol. 2008;36(7):929-46.

20. Pernice-Duca F. Staff and member perceptions of the clubhouse environment. Adm Policy Ment Health. 2010;37:345-56.

21. Pernice-Duca F. Factors influencing staff perceptions of the organizational environment of clubhouses. Adm Policy Ment Health. 2010;37:334-44.

22. Biegel D, Pernica-Duca F, Chang CW, D'Angelo L. Correlates of peer support in a Clubhouse setting. Community Ment Health J. 2013;49:249-59.

23. Coniglio FD, Hancock N, Ellis LA. Peer support within clubhouse: a grounded theory study. Community Ment Health J. 2012;48:153-60.

24. Norman C. The Fountain House movement, an alternative rehabilitation model for people with mental health problems, members' descriptions of what works. Scand J Caring Sci. 2006;20: 184-92.

25. Hancock N, Bundy A, Honey A, Helich S, Tamsett S. Measuring the later stages of the recovery journey: insights gained from clubhouse members. Community Ment Health J. 2013;49(3): 323-30.

26. Schroeder R. The seriously mentally ill older adult: perceptions of the patient-provider relationship. Perspect Psychiatr Care. 2013;49(1):30-40.

27. Charmaz K. Constructing grounded theory. 2nd ed. Thousand Oaks: Sage Publications; 2014.

28. Glaser BG, Strauss AL. The discovery of grounded theory: strategies for qualitative research. Thousand Oaks: Sage Publications; 1967.

29. Tanaka K. Clubhouse peer support among individuals with psychiatric illness. Int J Self Help Self Care. 2013;7(2):131-49.

30. Merriam Webster's collegiate dictionary. 3rd ed. Merriam Webster, Incorporated; 1993. Friendship. p. 467.

31. Anthony WA. The principle of personhood: the field's transcendent principle. Psychiatr Rehabil J. 2004;27:25.

32. Davidson L. Recovery from psychosis: What's love got to do with it? Psychosis. 2011;3(2):105-14.

33. Davidson L, Johnson A. It's the little things that count. Rebuilding a sense of self in schizophrenia. Tidsskrift for Psykisk Helsearbeid. 2013;10(3):258-63.

34. Davidson L, Haglund KE, Stayner DA, Rakfeldt J, Chinman MJ, Tebes JK. "It was just realizing...that life isn't one big horror": a qualitative study of supported socialization. Psychiatr Rehabil J. 2001;24(3):275-92.

35. Davidson L, Stayner DA, Nickou C, Styron TH, Rowe M, Chinman ML. "Simply to be let in": inclusion as a basis for recovery. Psychiatr Rehabil J. 2001;24(4):375-88.

36. Deegan PE. The independent living movement and people with psychiatric disabilities: taking back control over our own lives. Psychosoc Rehabil J. 1992;15:3-19.

37. McCarthy-Jones S, Davidson L. When soft voices die: auditory verbal hallucinations and a four letter word (love). Ment Health Relig Cult. 2012;16(4):367-83.

38. Davidson L. The importance of first-person experience making, or breaking, psychiatry. Pessoas Sintomas. 2009;9:46-52.

39. Davidson L, Strauss JS. Sense of self in recovery from severe mental illness. Br J Med Psychol. 1992;65:131-45.

40. Davidson L, Strauss JS. Beyond the biopsychosocial model: integrating disorder, health, and recovery. Psychiatry. 1995;58: 44-55.

41. Aristotle. Nicomachean ethics [T. Irwin, trans]. 2nd ed. Indianapolis/Cambridge: Hackett Publishing Company, Inc; 1999 [Original work published 384-322 BC].

42. Badhwar NK. Friends as ends in themselves. Philos Phenomenol Res. 1987;48(1):1-23. 
43. Cooper J. Aristotle on the forms of friendship. Rev Metaphys. 1977;30:619-48.

44. Cooper J. Friendship. In: Becker L, Becker C, editors. Encyclopedia of ethics [Internet]. London: Routledge; 2001 [cited 2015 May 20]. http://search.credoreference.com/content/entry/routethics/ friendship/0.

45. Blum LA. Friendship, altruism and morality. New York: Routledge; 2010.

46. Thomas L. Friendship. Synthese. 1987;72:217-36.

47. Barthold LS. Friendship and the ethics of understanding. Epoché. 2010;14(2):417-29.

48. Brewer T. Virtues we can share: friendship and Aristotelian ethical theory. Ethics. 2005;115:721-58.

49. Cocking D, Kennett J. Friendship and the self. Ethics. 1998;108:502-27.

50. Healy M. Civic friendship. Stud Philos Educ. 2011;30:229-40.

51. Helm BW. Friendship. In: Zalta EN, editor. The Standard encyclopedia of philosophy [Internet]. 2013 [cited 2015 May 20]. http://plato.stanford.edu/archives/fall2013/entries/friendship/.
52. Milgram E. Aristotle on making other selves. Can J Philos. 1987;17(2):361-76.

53. Sherman N. Aristotle on friendship and the shared life. Philos Phenomenol Res. 1987;47(4):589-613.

54. Shoeman F. Aristotle on the good of friendship. Australas $\mathbf{J}$ Philos. 1985;63(3):269-82.

55. Telfer E. Friendship. In: Proceedings of the Aristotelian Society. 1970/71; 71: 223-41.

56. Friendship White R. Ancient and modern. Int Philos Q. 1999;39(19-3):4.

57. Lincoln YS, Guba EG. Naturalistic inquiry. Thousand Oaks: Sage Publications; 1985.

58. Davidson A. What's love got to do with it? An Aristotelian and Christian reflection on the role of relationships in recovery [Baccalaureate thesis]. Boston, MA: Boston University; 2015. 